\title{
PATRIMÔNIO DOCUMENTAL NACIONAL: CONCEITOS E DEFINIÇÕES
}

\section{DOCUMENTARY NATIONAL HERITAGE: CONCEPTS AND DEFINITIONS}

Marcia Carvalho Rodrigues ${ }^{1}$

\section{RESUMO}

Este artigo apresenta conceitos fundamentais relativos à temática do patrimônio cultural, com ênfase na busca por uma definição, em nível nacional, de patrimônio documental. Os procedimentos metodológicos seguiram a abordagem dialética e a técnica da pesquisa em fontes bibliográficas e documentais. Os resultados apontam a inexistência de uma definição explícita, no Brasil, do que seja patrimônio documental, porém permitem observar a preocupação governamental com a preservação desta categoria patrimonial.

PALAVRAS-CHAVE: Patrimônio documental. Patrimônio cultural.

\section{ABSTRACT}

This article presents key concepts related to the theme of cultural heritage, with emphasis on the search for a definition, at the national level, of documentary heritage. The methodological procedures followed dialectical approach and research technique in bibliographic and documentary sources. The results indicate the absence of an explicit definition in Brazil of what documentary heritage is, but allow us to observe the government's concern for the preservation of this heritage category.

KEYWORDS: Documentary heritage. Cultural heritage.

\section{INTRODUÇÃO}

Observa-se, na literatura, que a noção de patrimônio documental está, muitas vezes, vinculada ao valor estético, cultural e/ou histórico de um documento ou coleção de documentos (acervos, fundos arquivísticos). Em geral, esta noção é a mesma que orienta bibliotecários, bibliófilos e livreiros na identificação de livros raros - um livro se torna raro quando adquire determinada característica, seja ela estética, através de uma encadernação luxuosa; histórica, por meio de sua data de impressão; ou cultural, por ter sido obra pioneira no estabelecimento de um conceito, apenas para citar alguns exemplos, que o torna excepcional em relação aos demais. Neste sentido, a definição do que vem a ser um livro raro se aproxima do conceito de patrimônio documental bibliográfico.

O presente texto, produzido a partir de uma das vertentes da pesquisa de doutoramento da autora, traz uma revisão de literatura sobre o uso da expressão "patrimônio documental", buscando apresentar o atual estado da arte em que se encontra o assunto em

\footnotetext{
${ }^{1}$ Professora do Instituto de Ciências Humanas e da Informação da Universidade Federal do Rio Grande (ICHI/FURG). Doutoranda do Programa de Pós-Graduação em Memória Social e Patrimônio Cultural da Universidade Federal de Pelotas (PPGMP/UFPel). E-mail: marciarodriguesfurg@gmail.com

Enviado em: 19/11/2015 - Aceito em: 18/01/2016
} 
questão, abordando autores e textos estrangeiros e nacionais. Apresenta as características de um estudo exploratório-descritivo de natureza qualitativa e está balizado pelo método dialético para a condução da análise.

Tecendo considerações a respeito de semelhanças e diferenças entre as definições e os conceitos elencados, busca-se apreender, através da revisão teórica, qual tem sido o tratamento dispensado ao patrimônio documental no Brasil, observando especialmente as estratégias utilizadas pela Biblioteca Nacional no sentido de salvaguardar a herança documental bibliográfica brasileira.

\title{
2 PATRIMÔNIO DOCUMENTAL: CONCEITOS E DEFINIÇÕES
}

O patrimônio cultural pode ser definido como o conjunto de manifestações de uma comunidade (incluindo suas práticas, costumes e valores, expressões artísticas e culturais, lugares e objetos) que é passado de uma geração a outra. É constituído dos mais diversos elementos e se apresenta, convencionalmente, dividido em patrimônio imaterial e patrimônio material, onde se entende por patrimônio imaterial tudo o que está relacionado aos modos de fazer das pessoas, às técnicas e habilidades, aos valores e às crenças; e por patrimônio material os produtos da criação humana, como os artefatos, os objetos e as construções, por exemplo.

O patrimônio material, por sua vez, pode ser constituído de diferentes categorias de elementos, dentre os quais se encontra o patrimônio documental.

Convém, neste momento, esclarecer em que consiste documento sob o ponto de vista da área da Ciência da Informação, uma vez que o presente estudo se insere no escopo das pesquisas de cunho biblioteconômico. As definições apresentadas a seguir foram extraídas de diferentes dicionários técnicos especializados.

"DOCUMENTO - Unidade de registro de informações, qualquer que seja o suporte ou formato." (ARQUIVO NACIONAL, 2005, p. 73, grifo do autor). Segundo o autor, este pode ser classificado, de acordo com o gênero documental ao qual pertence, em documento arquivístico, documento audiovisual, documento bibliográfico, documento cartográfico, documento digital, entre outros.

Reitz (2004, p. 228, trad. nossa) define documento como

\begin{abstract}
Um termo genérico para uma entidade física que consiste de qualquer substância na qual é registrada a totalidade ou uma porção de uma ou mais obras com o propósito de transmitir ou preservar o conhecimento. Nas palavras do teórico da comunicação Marshall McLuhan, um documento é o "meio" através do qual uma "mensagem" (informação) é comunicada. Formatos de documentos incluem manuscritos, publicação impressa (livros, folhetos, periódicos, relatórios, mapas, gravuras, etc.), microformas, mídias não impressas, recursos electrônicos, etc.
\end{abstract}

Para Cunha e Cavalcanti (2008), o termo documento pode ser definido, de maneira bastante simplificada, como "suporte de informação". Os autores trazem uma série de 
definições elaboradas por diferentes pensadores de variadas épocas. Todas as definições apresentam, em sua essência, a noção comum de que documento é algo através do qual se registram as informações, independente do suporte utilizado para tal. Corrobora com o Arquivo Nacional ao propor uma classificação dos documentos de acordo com sua tipologia. Numa tentativa de definir o que seja patrimônio documental e patrimônio bibliográfico, os autores fazem uso de remissivas, indicando as relações entre os termos da seguinte maneira: ao buscar a definição de patrimônio bibliográfico, o dicionário remete o leitor para o termo "acervo"; ao buscar a definição de patrimônio documental, o leitor é conduzido para a definição de "patrimônio arquivístico", o que permite inferir que há uma estreita relação entre o gênero documental e a composição dos patrimônios em questão.

Em relação à definição de patrimônio documental, o Programa Memória do Mundo da Organização das Nações Unidas para a Educação, a Ciência e a Cultura (UNESCO) o define como aquele "[...] que se encontra em bibliotecas em, em arquivos [e] que constitui uma parte primordial desta memória [do mundo] e que reflete a diversidade dos povos, das línguas e das culturas.”. (ABDELAZIZ, 1998, p. 5 apud PALMA PEÑA, 2011, p. 294, trad. nossa)

O Programa, criado em 1992, visa a: a) facilitar a preservação do patrimônio documental mundial através de técnicas adequadas; b) facilitar o acesso universal ao patrimônio documental e; c) possibilitar a conscientização mundial da existência e importância do patrimônio documental. (PROGRAMA MEMÓRIA DO MUNDO, 2002). A fim de alcançar os seus objetivos, o Programa opera em conjunto com outras iniciativas, formando uma rede de ações complementares entre si. Prevendo a realização de uma seleção dos bens que deverão ser considerados patrimônio para fins de Registro, estabelece critérios de avaliação de importância mundial do patrimônio documental, os quais buscam identificar se sua influência tem abrangência internacional, nacional ou regional. Os critérios definidos são:

1. Critério 1 - tempo: A idade, em termos absolutos, não converte um documento em importante, mas cada documento é um produto de seu tempo. Alguns documentos evocam especialmente sua época, que pode ter sido de crise, ou de mudança social ou cultural significativa. Um documento pode representar um novo descobrimento ou ser o "primeiro de seu tipo".

2. Critério 2 - lugar: O lugar de criação é um atributo chave de importância. Pode conter informação fundamental sobre uma localidade importante na história e na cultura mundial, ou a própria localização pode ter exercido uma influência decisiva nos acontecimentos ou fenômenos representados pelo documento. Pode descrever entornos físicos, cidades ou instituições desaparecidas desde então.

3. Critério 3 - pessoas: O contexto social e cultural de sua criação pode refletir aspectos significativos do comportamento humano, ou circunstâncias sociais, industriais, artísticas ou políticas. Pode captar a essência de grandes movimentos, transições, avanços ou regressões. Pode mostrar o impacto de indivíduos ou grupos chave.

4. Critério 4 - assunto e tema: $\mathrm{O}$ assunto pode referir-se a fatos históricos específicos ou desenvolvimentos intelectuais relacionados com as ciências naturais, sociais e humanas, a política, a ideologia, o esporte e a arte. 
5. Critério 5 - forma e estilo: O elemento pode possuir um notável valor estético, estilístico ou linguístico, ser um exemplar típico ou chave de um tipo de apresentação, costume ou meio, ou de um suporte ou formato desaparecido ou em vias de desaparição. (PROGRAMA MEMÓRIA DO MUNDO, 2002, p. 25)

Além dos cinco critérios elencados acima, deverão ser considerados ainda, quando do Registro, os seguintes elementos: a autenticidade do documento ou da coleção, a unicidade e insubstituibilidade da(s) obra(s), a raridade, a integridade, o grau de ameaça ao bem ou à coleção de bens e a possibilidade de implantação de um plano de gestão pela instituição solicitante.

A definição da UNESCO pretende ser ampla e abrangente, uma vez que servirá de referência para que outras instituições a adotem ou desenvolvam as suas próprias, porém se torna excludente no momento em que determina a seleção de alguns exemplares como representativos de uma sociedade por seu valor excepcional.

Neste artigo não serão tratadas as questões relativas à seleção e identificação de obras raras em bibliotecas, porém chama a atenção o fato de que os critérios de seleção da UNESCO lembrem bastante os critérios adotados por grande parte das bibliotecas para a identificação de raridades bibliográficas em seus acervos, assim como a metodologia proposta pela bibliotecária Ana Virgínia Pinheiro, em sua obra "Que é livro raro? Uma metodologia para o estabelecimento de critérios de raridade bibliográfica" (1989), a qual se baseia em cinco categorias fundamentais: aspecto histórico, aspectos bibliológicos, aspectos culturais, fontes bibliográficas e características do exemplar.

Voltando à questão da definição de patrimônio documental e reduzindo a escala de análise do global para o nacional, observam-se as legislações de cada país e a maneira como avaliam e valorizam seu patrimônio cultural. A Espanha, através da Lei n. 16, de 25 de junho de 1985, orienta o tratamento ao patrimônio histórico espanhol como um todo, porém dedica uma seção especial aos patrimônios documental e bibliográfico e aos arquivos, bibliotecas e museus. A lei distingue patrimônio documental de patrimônio bibliográfico, tendo como base para a diferenciação a tipologia documental.

No que concerne ao patrimônio documental, a legislação espanhola determina o seguinte:

1. Entende-se por documento, para os efeitos da presente Lei, toda expressão em linguagem natural ou convencional e qualquer outra expressão gráfica, sonora ou em imagem, recolhidas em qualquer tipo de suporte material, inclusos os suportes informáticos. Excluem-se os exemplares não originais de edições.

2. Formam parte do Patrimônio Documental os documentos de qualquer época gerados, conservados ou reunidos no exercício de sua função por qualquer organismo ou entidade de caráter público, pelas pessoas jurídicas em cujo capital participe majoritariamente o Estado ou outras entidades públicas e pelas pessoas privadas, físicas ou jurídicas, gestoras de serviços públicos no que se relacione com a gestão destes serviços.

3. Formam, igualmente, parte do Patrimônio Documental os documentos com uma antiguidade superior a quarenta anos, gerados, conservados ou reunidos no exercício de suas atividades pelas entidades e associações de caráter político, sindical ou religioso e pelas entidades, fundações e associações culturais e educativas de caráter privado. 
4. Integram, também, o Patrimônio Documental os documentos com uma antiguidade superior a cem anos, gerados, conservados ou reunidos por quaisquer outras entidades particulares ou pessoas físicas.

5. A Administração do Estado poderá declarar constitutivos do Patrimônio Documental aqueles documentos que, sem alcançar a antiguidade indicada nos apartados anteriores, mereçam esta consideração. (ESPANHA, 1985, Art. 49, trad. nossa)

Por patrimônio bibliográfico a legislação espanhola entende:

1. Formam parte do Patrimônio Bibliográfico as bibliotecas e coleções bibliográficas de titularidade pública e as obras literárias, históricas, científicas ou artísticas de caráter unitário ou seriado, em escritura manuscrita ou impressa, das quais não conste a existência de ao menos três exemplares nas bibliotecas ou serviços públicos. Presumir-se-á que existe este número de exemplares no caso de obras editadas a partir de 1958.

2. Também formam parte do Patrimônio Histórico Espanhol e lhes será aplicado o regime correspondente ao Patrimônio Bibliográfico os exemplares resultantes de edições de películas cinematográficas, discos, fotografias, materiais audiovisuais e outros similares, qualquer que seja seu suporte material, desde que não constem ao menos três exemplares nos serviços públicos, ou um no caso de películas cinematográficas. (ESPANHA, 1985, Art. 50, trad. nossa)

Torna-se necessária uma ressalva no sentido de elucidar o sistema administrativo espanhol, uma vez que existem leis nacionais, como a própria Constituição, por exemplo (emanada da Administração Geral do Estado), e leis oriundas das Comunidades Autônomas. As Comunidades, porém, tem competência administrativa para gerir seus patrimônios, tendo em conta que ao Estado cabe a administração, defesa e conservação do patrimônio como um todo. Assim, compete às Comunidades Autônomas espanholas firmar convênios para gestão de bibliotecas, arquivos e museus junto ao Ministério da Cultura, visando à realização de um trabalho conjunto no campo dos patrimônios bibliográfico e documental, tanto em âmbito local quanto nacional. Hernández Hernandez (1996) observa a importância desta dinâmica colaborativa no sentido de estabelecer um diálogo permanente entre o Estado e as Comunidades Autônomas:

Assim se evitarão rivalidades desnecessárias que nada tem a ver com a cultura, mas sim muito com posicionamentos personalistas que não deixam transparecer o valor universal do nosso patrimônio que, apesar de ter sido gerado em um contexto sociocultural e político concreto, pertence a todo o povo espanhol, sem deixar de reconhecer as peculiaridades próprias de sua origem e desenvolvimento cultural. (HERNÁNDEZ HERNANDEZ, 1996, p. 26, trad. nossa)

Deixando de lado a questão administrativa e trazendo novamente as definições apresentadas, percebe-se que as características que norteiam a formação do patrimônio documental arquivístico espanhol são pautadas em critérios de antiguidade e caráter público ou privado do sujeito criador/mantenedor da documentação. Já a definição de patrimônio bibliográfico atenta para o fato de desconsiderar as obras publicadas a partir de 1958 como parte integrante do patrimônio, uma vez que foi neste ano que se criou a lei do depósito legal na Espanha. Outra observação a ser feita diz respeito aos tipos de obra que poderão vir a ser 
considerados patrimônio bibliográfico: livros e materiais audiovisuais. Desantes (1987, p. 85 apud HERNÁNDEZ HERNANDEZ, 1996, p. 22, trad. nossa)

[...] opina que o legislador adoece de uma visão unitária do que deve ser um documento e, ao mesmo tempo, do regime jurídico e técnico apropriado, levandolhe a integrar uma série de materiais que são autênticos documentos dentro do patrimônio Bibliográfico, porém sempre fazendo uma relação que resulta incompleta e insuficiente.

A legislação espanhola, por sua vez, avança no sentido de apresentar, mesmo que de forma insatisfatória, uma diferenciação dos bens que compõem cada patrimônio em função da sua tipologia, porém as definições propostas permanecem vinculadas às características de excepcionalidade e raridade, especialmente a definição de patrimônio bibliográfico.

A fim de aproximar a definição de patrimônio documental de nossa realidade latinoamericana, apresenta-se o conceito definido na Lei n. 1.379, de 15 de janeiro de 2010, da Colômbia, que descreve o patrimônio documental nacional como sendo o:

Conjunto de obras ou documentos que conformam uma coleção nacional, que inclui as coleções recebidas por depósito legal e toda obra que se considere herança e memória, ou que contribua para a construção da identidade da Nação em sua diversidade. Inclui livros, folhetos e manuscritos, microformas, material gráfico, cartográfico, seriado, sonoro, musical, audiovisual, recursos eletrônicos, entre outros. (COLÔMBIA, 2010, Art. 2, trad. nossa)

A definição colombiana para patrimônio documental difere das definições dadas pela UNESCO e pela Espanha. A UNESCO defende a seleção de bens com base na sua excepcionalidade. A legislação espanhola, apesar de mais criteriosa no sentido de diferenciar as áreas do patrimônio em bibliográfico e documental, também tende para a antiguidade e a raridade e exclui os livros oriundos de doação via depósito legal. A Colômbia, por sua vez, considera patrimônio documental nacional toda a produção intelectual originada no país, acrescida de obras cujo valor intrínseco venha a contribuir para a formação da identidade nacional, sem fazer distinção entre os gêneros documentais (documentos de arquivo ou de biblioteca).

Ao observar as definições apresentadas, não se pode deixar de levar em consideração o fato da UNESCO, por se tratar de entidade de atuação internacional, ao elaborar uma definição de patrimônio documental, buscar abarcar o patrimônio cultural mundial, observando as particularidades de cada país e de seus patrimônios documentais nacionais. Daí a diferença exacerbada em relação à definição proposta pela Colômbia, a qual busca enaltecer a produção documental nacional, sendo este, como poderá ser observado mais adiante no texto, um dos objetivos fundamentais das bibliotecas nacionais, consolidado especialmente através da prática do depósito legal. A legislação espanhola é, também, bastante generalista nas suas definições, porém desconsidera a produção intelectual recente como parte do patrimônio documental nacional.

Elvira-Julieta Miguélez González, professora de Biblioteconomia e Documentação na Universidade de Salamanca, descreve o patrimônio documental como sendo 
[...] formado por livros e documentos, que se conservam em arquivos e bibliotecas. Os primeiros acolhem, essencialmente, os fundos denominados documentais e são produto da atividade administrativa de diversas instituições. As segundas se ocupam dos fundos bibliográficos, e sua origem se encontra, normalmente, na atividade criadora do homem. (MIGUÉLEZ GONZÁLEZ, 1995, p. 281, trad. nossa)

Claudia B. Bazán e Patrícia E. Monsalvo, ambas bibliotecárias e pesquisadoras argentinas, baseadas na legislação sobre patrimônio cultural argentina, seguem a mesma linha de raciocínio. Para elas,

Um documento representa o mecanismo inventado pela humanidade para valorizar e transmitir conhecimentos às gerações futuras e ser fonte de prova factual. Concebido em sua tripla dimensão: suporte físico, criação intelectual e mensagem informativa, cujo significado é constantemente atualizado no processo de comunicação, o documento é fonte permanente de informação, é a memória da cultura humana e o testemunho dos acontecimentos da história, da vida contemporânea e do trabalho global da sociedade. Esta é a razão pela qual deve ser conservado e protegido. (BAZÁN; MONSALVO, 2009, trad. nossa)

As autoras diferenciam os documentos de biblioteca dos documentos de arquivo de maneira bastante simplista: o conjunto de documentos gerados por um país se constitui, segundo elas, dos publicados e dos inéditos. Assim, defendem a ideia de que as instituições responsáveis pela salvaguarda destes seriam, respectivamente, as bibliotecas nacionais e os arquivos nacionais, salvo exceções onde há uma mescla destes materiais.

Cabral (2013, p. 8) apresenta como definição de patrimônio bibliográfico, um “[...] conjunto de documentos depositados numa biblioteca.", os quais, segundo a autora, poderão ou não ser nacionais, porém salienta que somente a partir da análise do conjunto de obras provenientes da produção intelectual nacional seria possível perceber a identidade coletiva de um povo:

\begin{abstract}
A produção intelectual, tipográfica ou artística exclusiva dum país constitui um substrato de grande valor e desse patamar sairão os denominados tesouros nacionais, autêntico núcleo duro das bibliotecas patrimoniais, obrigatoriamente em número muito restrito. Por definição, os tesouros nacionais tornam-se então, e de forma inquestionável, elementos construtores da identidade. (CABRAL, 2013, p. 8, grifo do autor)
\end{abstract}

A autora denomina bibliotecas patrimoniais as bibliotecas "[...] que detêm tesouros nacionais" (CABRAL, 2013, p. 8), o que vai ao encontro dos objetivos de criação das bibliotecas nacionais, assim toda biblioteca nacional poderia ser considerada, também, uma biblioteca patrimonial.

Rosa María Fernández de Zamora, doutora e pesquisadora na área de Biblioteconomia e patrimônio na Universidade do México, entende o patrimônio documental como

[...] o conjunto de bens culturais herdados do passado e o criado pela própria geração, pois o patrimônio documental não se refere unicamente a documentos e livros antigos, senão a todo documento de caráter singular, único ou valioso, do presente ou do passado porque patrimônio pode ser também o que estamos criando e deixaremos para as gerações futuras. (FERNÁNDEZ DE ZAMORA, 2014, p. 2, trad. nossa) 
Orlanda Jaramillo e Sebastián-Alejandro Marín-Agudelo, ambos pesquisadores da Universidade de Antióquia (Colômbia), definem patrimônio bibliográfico como:

[...] todo documento que represente ou seja a expressão de identidade cultural de um conglomerado social, comunidade ou nação, editado em qualquer suporte (papel, magnético, acetato, óptico ou microforma), sem importar o formato de sua apresentação (livro ou monografia, folheto, pôster, cartografia, revista, boletim ou jornal); que se produz com a intenção de difundir um saber ou ideia de um grupo ou comunidade, com fins de distribuição, ou que é produto de um momento histórico ou de valor simbólico para determinada comunidade, dado que fornece e assegura sua identidade cultural. Em todo caso, o documento bibliográfico patrimonial cumpre com ao menos uma das seguintes características: originalidade (autenticidade), unicidade (insubstituibilidade), valor simbólico, valor de conteúdo ou valor estético. (JARAMILLO; MARÍN-AGUDELO, 2014, p. 428, trad. nossa)

No referido artigo, os autores defendem uma diferenciação entre patrimônio bibliográfico e patrimônio documental, sendo o mote da reflexão a noção de documento presente na área da Ciência da Informação, tratada sob diferentes enfoques na Biblioteconomia, na Arquivologia e na Museologia (campos científicos da área), as quais, por sua vez, o interpretam segundo sua finalidade, suporte físico, contexto, forma de acesso e origem ou procedência.

Para Jaramillo e Marín-Agudelo (2014, p. 426, grifo do autor, trad. nossa),

Os livros e textos impressos constituem o patrimônio bibliográfico, o qual forma parte de um conjunto mais amplo de objetos que tem como característica essencial uma inscrição de dados. Estes são o resultado material das práticas da cultura escrita e a este conjunto denominamos patrimônio documental. Assim, o patrimônio documental é muito mais amplo que os textos, livros impressos, manuscritos e os escritos criados em razão de uma atividade qualquer, como são os documentos de arquivo, e inclui qualquer objeto que leve uma inscrição ou mensagem sob uma perspectiva antropológica, como por exemplo os objetos de museus.

Assim, a discussão em torno de uma definição de patrimônio documental e de patrimônio bibliográfico se esgotaria na medida em que a noção de patrimônio documental, ou seja, um conjunto de bens patrimoniais de natureza documental, abarcaria toda a tipologia documental existente, incluindo tanto materiais de arquivo quanto de biblioteca. Desta forma, o patrimônio documental como um todo poderia ser categorizado em patrimônio documental arquivístico, patrimônio documental bibliográfico, patrimônio documental audiovisual, patrimônio documental cartográfico, patrimônio documental digital, e assim por diante.

Com base nestes conceitos, poder-se-ia pensar o patrimônio documental de uma nação como o conjunto de manifestações intelectuais, científicas ou artísticas, oriundas da atividade intelectual de seus cidadãos, materializadas através dos mais diversos suportes de registro do conhecimento humano.

Observa-se, ainda, que os conceitos de patrimônio documental apresentados nas normas jurídicas tem como base o referencial teórico relativo ao patrimônio cultural, o que vai ao encontro das políticas internacionais e/ou nacionais de preservação dos bens representativos do patrimônio cultural. Assim, justificam-se as definições de patrimônio documental arquivístico e patrimônio documental bibliográfico como bens distintos em 
função da tipologia dos exemplares que lhes constituem, permanecendo cada um sob a responsabilidade de uma instituição específica, respectivamente: arquivo e biblioteca. Da mesma forma, compreende-se a pertinência dos acervos bibliográficos nacionais reunidos a partir de doações por depósito legal para fins de construção de identidade coletiva nacional. Do contrário, permanecem as concepções de excepcionalidade e de raridade bibliográfica como elementos norteadores na seleção do patrimônio documental de uma nação, o que, muitas vezes, difere das suas propostas de identidade coletiva.

\section{A PRESERVAÇÃO DO PATRIMÔNIO DOCUMENTAL BRASILEIRO}

No Brasil, primeiro país latino-americano a criar uma instituição pública voltada à preservação do patrimônio cultural, tem-se, no movimento modernista, a gênese da valorização de um passado até então escondido: o passado mestiço.

As mudanças sociais, econômicas e políticas, ensejadas pela Revolução de 1930, exigirão uma nova organização do Estado brasileiro, onde a valorização da nacionalidade é essencial para a estruturação de um projeto de país e para a afirmação do regime. (TORELLY, 2012)

Até a eclosão do modernismo, com a Semana de Arte Moderna em 1922, o Brasil vinha sendo um país, embora independente deste 1889, consumidor e reprodutor da arte, da cultura e dos costumes europeus. Somente a partir da década de 1920 o país avança em relação às atividades da vida social e econômica: surgem as elites vinculadas ao comércio e à indústria, amplia-se a classe média, importantes intelectuais e pensadores vanguardistas se destacam, exercendo influência sobre a forma de pensar a nação.

Dentre os citados intelectuais, se destaca, na época, o escritor Mário de Andrade por defender uma integração dinâmica entre o passado e o presente da nação, alegando a necessidade de criação de um vínculo vivo do passado com a atualidade, do contrário, segundo o própio autor, a tradição, por si só, não teria valor algum. (FUNDAÇÃO GETÚLIO VARGAS, 2015)

A política cultural desenvolvida durante o governo de Getúlio Vargas (1930-1945) incluiu, dentre outras ações voltadas para a construção da identidade nacional, a criação de instituições voltadas à gestão e preservação da cultura e a nomeação de diversos intelectuais para a sua administração. Tem-se, portanto, a seguinte configuração no início da década de 1930: a indicação do arquiteto Lúcio Costa para a direção da Escola Nacional de Belas Artes; em 1931 o escritor Manuel Bandeira foi convidado para presidir o Salão Nacional de Belas Artes; o advogado Gustavo Capanema foi nomeado em 1934 para o cargo de Ministro da Educação e da Saúde Pública, tendo como seu assessor de gabinete o poeta Carlos Drummond da Andrade; Mário de Andrade passa a dirigir o Departamento de Cultura da Municipalidade de São Paulo a partir de 1935. (FUNDAÇÃO GETÚLIO VARGAS, 2015)

Em 1936, a convite do então Ministro da Educação e Saúde Pública, Gustavo Capanema, Mário de Andrade, elabora o anteprojeto de criação de uma instituição de caráter federal voltada às questões preservacionistas. "Ainda hoje impressiona o anteprojeto por sua 
clarividência e contemporaneidade, decorridos quase 80 anos." (INSTITUTO DO PATRIMÔNIO HISTÓRICO E ARTÍSTICO NACIONAL, 2015). No ano seguinte, em 1937 se dá a criação do Serviço do Patrimônio Histórico e Artístico Nacional (SPHAN). Tal iniciativa marca o princípio das ações governamentais voltadas à preservação do patrimônio cultural nacional. Até então, conforme observa Santos (2000, p. 29),

\begin{abstract}
Salvo algumas exceções, podemos dizer que o que caracterizou a postura do governo no Brasil, ao longo do tempo, foi a omissão frente à lenta destruição do nosso patrimônio cultural. Somente um ou outro particular, colecionador ou intelectual afeito às coisas históricas, se lembrava de solicitar defesa e proteção, assim mesmo, somente em relação a monumentos arquitetônicos porque, quanto ao patrimônio popular, não havia preocupação.
\end{abstract}

Com a criação do SPHAN surgiu, em 30 de novembro de 1937, o Decreto-lei n. ${ }^{\circ} 25$, que sistematiza a proteção do Patrimônio Histórico e Artístico Nacional. É, até os dias de hoje, um dos principais instrumentos da administração pública para a efetivação da proteção ao patrimônio cultural brasileiro. No referido documento, é reconhecido como patrimônio histórico e artístico nacional

[...] o conjunto dos bens móveis e imóveis existentes no país e cuja conservação seja de interesse público, quer por sua vinculação a fatos memoráveis da história do Brasil, quer por seu excepcional valor arqueológico ou etnográfico, bibliográfico ou artístico. (BRASIL, 1937, Art. 1)

Está explícito, no referido Artigo, o reconhecimento de bens de natureza bibliográfica como parte do patrimônio cultural da nação. Mais adiante, no Capítulo V - Disposições gerais, o decreto menciona o seguinte:

Os negociantes de antiguidades, de obras de arte de qualquer natureza, de manuscritos e livros antigos ou raros são obrigados a um registro especial no Serviço do Patrimônio Histórico e Artístico Nacional, cumprindo-lhes outrossim apresentar semestralmente ao mesmo relações completas das coisas históricas e artísticas que possuírem. (BRASIL, 1937, Art. 26)

$\mathrm{Na}$ sequencia dos artigos, são fixadas as taxas e valores de multas incidentes sobre o não cumprimento das exigências impostas pelo decreto.

O Decreto n. ${ }^{\circ}$ 25/1937 não apresenta uma definição do que vem a ser o patrimônio documental da nação, mas reconhece os manuscritos e livros raros como bens culturais dignos de preservação, firmando a proposição de preservação de um patrimônio composto por obras de excepcional valor bibliográfico. Tal prerrogativa corrobora com a proposta, bem mais recente, de reconhecimento e valorização do patrimônio documental elaborada pela UNESCO, através do Programa Memória do Mundo.

A partir da criação do SPHAN, o qual, após reestruturação administrativa sofreu alteração no nome, passando a se chamar Instituto do Patrimônio Histórico e Artístico Nacional (IPHAN), ampliou-se a visibilidade da necessidade de preservação dos bens culturais, o que propiciou a criação de um ambiente favorável à discussão e à problematização do patrimônio cultural no país. 
Em nível global, após a década de 1950, houve uma ampliação das discussões em torno do patrimônio cultural, uma vez que se constatou a perda de muitos bens em decorrência das duas Grandes Guerras, o que resultou em uma série de recomendações, cartas e convenções, por parte da UNESCO, como a Convenção para a proteção de bens culturais móveis em caso de conflito armado (1954) e a Recomendação sobre medidas destinadas a proibir e impedir a exportação, a importação e a transferência de propriedade ilícitas de bens culturais (1964). Ambos os documentos incluem, em suas definições sobre bens culturais, o patrimônio documental.

Em 1970, o I Encontro de Governadores de Estado, Secretários Estaduais da Área Cultural, Prefeitos de Municípios Interessados e Presidentes e Representantes de Instituições Culturais, promovido pelo Ministério da Educação e Cultura, deu origem ao Compromisso de Brasília. Neste documento fica explícita a preocupação com os bens de natureza arquivística e bibliográfica:

11. Recomenda-se a defesa do acervo arquivístico, de modo a ser evitada a destruição de documentos, ou tendo por fim preservá-los convenientemente, para cujo efeito será apreciável a colaboração do Arquivo Nacional com as congêneres repartições estaduais e municipais.

\section{$[\ldots]$}

13. Recomenda-se a conservação do acervo bibliográfico, observadas as normas técnicas oferecidas pelos órgãos federais especializados na defesa, instrumentação e valorização desse patrimônio. (BRASIL, 1970 apud BRASIL; FUNDAÇÃO NACIONAL PRÓ-MEMÓRIA, 1980, p. 97)

A Constituição federal de 1988, por sua vez, define bens culturais de forma ampla:

$$
\begin{aligned}
& \text { Constituem patrimônio cultural brasileiro os bens de natureza material e imaterial, } \\
& \text { tomados individualmente ou em conjunto, portadores de referência à identidade, à } \\
& \text { ação, à memória dos diferentes grupos formadores da sociedade brasileira, nos } \\
& \text { quais se incluem: } \\
& \text { I - as formas de expressão; } \\
& \text { II - os modos de criar, fazer e viver; } \\
& \text { III - as criações científicas, artísticas e tecnológicas; } \\
& \text { IV - as obras, objetos, documentos, edificações e demais espaços destinados às } \\
& \text { manifestações artístico-culturais; } \\
& \text { V - os conjuntos urbanos e sítios de valor histórico, paisagístico, artístico, } \\
& \text { arqueológico, paleontológico, ecológico e científico. (BRASIL, 1988, Art. 216) }
\end{aligned}
$$

Aborda, ainda, na alínea 2 do Artigo 216 a responsabilidade pela gestão da documentação governamental, a qual pode ser confirmada a partir da missão do Arquivo Nacional. Não aborda, porém, em nenhum momento, a gestão do patrimônio bibliográfico nacional.

Conforme pode ser observado até este ponto, dentre os bens culturais vistos pela sociedade como dignos de preservação estão os impressos, especialmente o livro. No Brasil, 
de uns anos para cá, vem sendo desenvolvidas algumas iniciativas para a identificação, valorização e preservação dos fundos antigos e raros. Nesse sentido, a Biblioteca Nacional tem contribuído significativamente através do Plano Nacional de Recuperação de Obras Raras (PLANOR), cujos principais objetivos são:

Identificar, coletar, reunir e disseminar através da Fundação Biblioteca Nacional informações sobre acervos raros existentes no Brasil.

Fornecer orientações sobre procedimentos técnicos na identificação, organização, tratamento técnico e gestão desse patrimônio, conforme normas adotadas pela Fundação Biblioteca Nacional.

Prestar assessoria técnica a outras instituições com a finalidade de orientar quanto à organização e preservação de acervos raros existentes no País, além de desenvolver programas de formação e aperfeiçoamento de mão de obra especializada (BIBLIOTECA NACIONAL, 2006)

No âmbito latino-americano, a Associação de Estados Ibero-americanos para o Desenvolvimento das Bibliotecas Nacionais de Iberoamérica (ABINIA) tem contribuído de forma significativa para a valorização e preservação do patrimônio documental bibliográfico dos países participantes. Dentre seus objetivos específicos está a elaboração de um catálogo coletivo de monografias dos séculos XVI a XIX depositadas nos acervos das bibliotecas nacionais ibero-americanas: o Novum Regestrum. A Biblioteca Nacional, através do PLANOR, é coparticipante no projeto do catálogo e tem trabalhado para disponibilizar as descrições de obras publicadas entre 1501 e 1900, pertencentes ao seu acervo e ao acervo das instituições brasileiras cadastradas no PLANOR.

O Brasil não define o que é, ou de que bens é constituído o patrimônio documental brasileiro, porém apresenta, através das competências de duas importantes instituições nacionais - a Biblioteca Nacional e o Arquivo Nacional - explícita distinção entre o que vem a ser patrimônio documental bibliográfico e patrimônio documental arquivístico em função dos gêneros documentais que cada instituição gerencia.

No que se refere à Biblioteca Nacional,

Sua missão precípua é de preservar, atualizar e divulgar esse patrimônio, constituído de todas as publicações realizadas no e sobre o país, nos diferentes suportes, com o objetivo de garantir a todos os cidadãos, desta e das futuras gerações, o acesso a toda a memória cultural que integra seu acervo. (FUNDAÇÃO BIBLIOTECA NACIONAL, 2004, p. 3)

Sobre o Arquivo Nacional, este tem por finalidade

[...] implementar a política nacional de arquivos, definida pelo Conselho Nacional de Arquivos - órgão central do Sistema Nacional de Arquivos, por meio da gestão, do recolhimento, do tratamento técnico, da preservação e da divulgação do patrimônio documental do governo federal, garantindo pleno acesso à informação, visando apoiar as decisões governamentais de caráter político-administrativo, o cidadão na defesa de seus direitos e incentivar a produção de conhecimento científico e cultural. (ARQUIVO NACIONAL, [2015], p. 3) 
Na missão da Biblioteca Nacional transparece o entendimento de um patrimônio bibliográfico nacional composto por obras produzidas em território nacional e/ou cujo tema se refira ao país, independentemente de suporte físico, ou seja, reconhece diferentes gêneros documentais como parte integrante deste conjunto, como livros, manuscritos, documentos audiovisuais, cartográficos, iconográficos etc. Salienta, ainda, a permanente atualização deste acervo, que se dá, em grande parte, via depósito legal, e o reconhece como patrimônio nacional.

\section{CONSIDERAÇÕES FINAIS}

A Constituição brasileira, principal instrumento legal de efetivação da cidadania, salienta a necessidade de preservação e valorização do patrimônio cultural da nação, o que permite inferir que o patrimônio documental é visto e reconhecido como instrumento de validação das políticas de governo.

O enfoque deste estudo residiu na busca por uma definição do patrimônio documental bibliográfico brasileiro, o que resultou na constatação da inexistência desta, o que, por sua vez, não inviabiliza a realização de inferências no sentido de determinar quais bens fazem parte do patrimônio documental bibliográfico nacional. É pertinente pensar o mesmo como o conjunto de documentos oriundos da produção intelectual brasileira, formado a partir de diferentes coleções de obras, como é o caso do acervo inicial da Biblioteca Nacional cuja origem se encontra na Biblioteca real de Dom João. O depósito legal apresenta, portanto, relevante contribuição no sentido de aumentar e atualizar a coleção, porém seu impacto pode ser sentido, também, no delineamento do perfil do acervo, dada a obrigatoriedade do envio de publicações nacionais via legislação.

Torna-se relevante, neste momento, destacar três importantes finalidades do depósito legal: 1) a finalidade legal, ao assegurar os direitos de propriedade intelectual e os direitos do autor, tornando obrigatório, por força de lei, o envio de um ou mais exemplares à instituição competende para fins de registro e tombamento; 2) a finalidade política, ao servir de instrumento de controle das publicações de um país, possibilitando a elaboração da bibliografia nacional e; 3) a finalidade cultural, ao buscar a preservação do patrimônio bibliográfico com a criação de uma coleção de memória nacional através dos exemplares compulsoriamente encaminhados à instituição.

Percebe-se, através do discurso oficial, a importância dada ao patrimônio documental da nação, ainda que não se apresente sua definição em nenhum dos documentos mencionados. Neste sentido, deve-se atentar para o fato de que os conceitos que proporcionarão a base para a determinação de quais manifestações documentais apresentam elementos culturais significativos para a nação deverão se pautar na sua definição de patrimônio cultural.

Através desta pesquisa foi possível perceber a necessidade de elaborar uma definição, em nível nacional, do que vem a ser o patrimônio documental brasileiro, a fim de elucidar 
possíveis equívocos de ordem jurídica e/ou administrativa, uma vez que para se efetivar a sua proteção legal é necessário que estes tenham sido incluídos na agenda cultural nacional.

Por fim, agregue-se a tudo o que foi mencionado, a necessidade de preservar, difundir e socializar o patrimônio documental, a fim de proporcionar condições aos cidadãos brasileiros de acessar e estudar estas fontes de informação, ampliando assim seus conhecimentos, contribuindo para a formação de sua consciência histórica e reconhecimento identitário.

\section{REFERÊNCIAS}

ARQUIVO NACIONAL (Brasil). Competências. Rio de Janeiro, [2015]. Disponível em: $<$ http://goo.gl/TiwOcV>. Acesso em: 24 ago. 2015.

ARQUIVO NACIONAL (Brasil).. Dicionário brasileiro de terminologia arquivística. Rio de Janeiro, 2005. Disponível em: < http://goo.gl/bgrpEj>. Acesso em: 24 ago. 2015.

BAZÁN, Claudia B.; MONSALVO, Patrícia E. Legislación sobre preservación del patrimonio documental y bibliográfico argentino. [Buenos Aires, 2009]. Disponível em: <http://goo.gl/uHsxri>. Acesso em: 26 nov. 2014.

BIBLIOTECA NACIONAL (Brasil). Plano Nacional de Recuperação de Obras Raras. PLANOR. Rio de Janeiro, c2006. Disponível em: <http://goo.gl/fFy6FM>. Acesso em: 12 set. 2015.

BRASIL. Constituição da República Federativa do Brasil de 1988. Disponível em: <http://goo.gl/GzQjyJ>. Acesso em: 12 set. 2015.

BRASIL. Decreto-lei n. ${ }^{\circ}$ 25, de 30 de novembro de 1937. Organiza a proteção do patrimônio histórico e artístico nacional. Disponível em: <http://goo.gl/aJ1vB2>. Acesso em: 12 set. 2015.

BRASIL. Ministério da Educação e Cultura. Secretaria do Patrimônio Histórico e Artístico Nacional; FUNDAÇÃO NACIONAL PRÓ-MEMÓRIA. Proteção e revitalização do patrimônio cultural no Brasil: uma trajetória. Brasília, 1980. Disponível em: <http://goo.gl/ad4I3l>. Acesso em: 12 set. 2015.

CABRAL, Maria Luísa Rosendo. Património bibliográfico e bibliotecas na construção da identidade colectiva: entre um conceito e o seu desenvolvimento, 1750-1800. 2013. Tese (Doutorado em História Moderna) - Universidade Nova de Lisboa, Faculdade de Ciências Sociais e Humanas, Lisboa, 2013. Disponível em: <http://goo.gl/vxLTfD>. Acesso em: 26 nov. 2014.

COLÔMBIA. Ley 1379 de 2010 (Enero 15): por la cual se organiza la red nacional de bibliotecas públicas y se dictan otras disposiciones. Disponível em: <http://goo.gl/Z1Ugqq >. Acesso em: 14 abr. 2015. 
CUNHA, Murilo Bastos da; CAVALCANTI, Cordélia Robalinho de Oliveira. Dicionário de Biblioteconomia e Arquivologia. Brasília: Briquet de Lemos/Livros, 2008.

ESPANHA. Ley 16/1985, de 25 de junio, del Patrimonio Histórico Español. Disponível em: <http://goo.gl/I3dOvt>. Acesso em: 15 abr. 2015.

FERNÁNDEZ DE ZAMORA, Rosa María. Conocer, valorar y difundir el patrimonio documental de América Latina y el Caribe. In: WORLD LIBRARY AND INFORMATION CONGRESS: IFLA GENERAL CONFERENCE AND ASSEMBLY, 75., 2009, Milão. Programme and proceedings. [S.l.]: IFLA, c2014. Disponível em: <http://goo.gl/99eurJ>. Acesso em: 15 abr. 2015.

FUNDAÇÃO BIBLIOTECA NACIONAL. Relatório de atividades 2003. Rio de Janeiro, 2004. Disponível em: <http://goo.gl/Y5GXql>. Acesso em: 15 abr. 2015.

FUNDAÇÃO GETÚLIO VARGAS. Centro de Pesquisa e Documentação de História Contemporânea do Brasil. Navegando na História: a Era Vargas. Rio de Janeiro, 2015. Disponível em: <https://goo.gl/b0ljFf>. Acesso em: 15 jan. 2016.

HERNÁNDEZ HERNANDEZ, Francisca. El patrimonio documental y bibliográfico. Revista General de Información y Documentación, Madrid, v. 6, n. 1, 1996. Disponível em: <http://goo.gl/w3ROmH>. Acesso em: 15 abr. 2015.

INSTITUTO DO PATRIMÔNIO HISTÓRICO E ARTÍSTICO NACIONAL. Mário de Andrade. Brasília, 2015. Disponível em: <http://goo.gl/92lKYS>. Acesso em: 15 jan. 2016.

JARAMILLO, Orlanda; MARÍN-AGUDELO, Sebastián-Alejandro. Patrimonio bibliográfico en la biblioteca pública: memorias locales e identidades nacionales. El profesional de la información, Barcelona, v. 23, n. 4, p. 425-432, Julio/Agosto 2014. Disponível em: <http://goo.gl/ECCEmr>. Acesso em: 13 abr. 2015.

MIGUÉLEZ GONZÁLEZ, Elvira-Julieta. Concepto y método de restauración del documento gráfico. Berceo, Logronho, n. 128, p. 281-290, 1995. Disponível em: <http://goo.gl/GsrOqf>. Acesso em: 15 abr. 2015.

PALMA PEÑA, Juan Miguel. La socialización del patrimonio bibliográfico y documental de la humanidad desde la perspetiva de los derechos culturales. Revista General de Información y Documentación, México, v. 21, p. 291-312, 2011. Disponível em: <http://goo.gl/pqAY8O>. Acesso em: 14 abr. 2015.

PINHEIRO, Ana Virgínia. O que é livro raro? Uma metodologia para o estabelecimento de critérios de raridade bibliográfica. Rio de Janeiro: Presença, 1989.

PROGRAMA MEMÓRIA DO MUNDO. Diretrizes para a salvaguarda do patrimônio documental. Elaborado por Ray Edmondson. Ed. rev. [S.1.]: Divisão da Sociedade da Informação/Unesco, 2002. Disponível em: <http://goo.gl/fZ621k>. Acesso em: 14 ago. 2015.

REITZ, Joan M. Dictionary for Library and Information Science. Westport, Connecticut: Libraries Unlimited, 2004. 
SANTOS, Fausto Henrique dos. Metodologia aplicada em museus. São Paulo: Mackenzie, 2000.

TORELLY, Luiz P. P. Notas sobre a evolução do conceito de patrimônio cultural. Fórum Patrimônio, Belo Horizonte, v. 5, n. 2, jul./dez. 2012. Não paginado. Disponível em: <http://goo.gl/zjWzSV>. Acesso em: 24 ago. 2015.

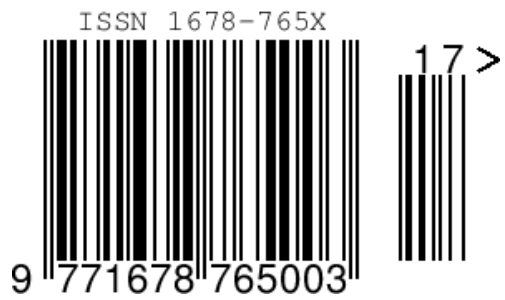

RODRIGUES, Marcia Carvalho. Patrimônio documental nacional: conceitos e definições. RDBCl:

Revista Digital de Biblioteconomia e Ciência da Informação, Campinas, SP, v. 14, n. 1, p. 110-125, fev. 2016. ISSN 1678-765X. Disponível em:

<http://periodicos.sbu.unicamp.br/ojs/index.php/rdbci/article/view/8641846>. Acesso em: 01 fev. 2016. doi:http://dx.doi.org/10.20396/rdbci.v14i1.8641846. 